\title{
El movimiento anticomunista en Jalisco durante los años setenta
}

\author{
The anti-communist movement in Jalisco \\ in the seventies
}

\author{
doi: http://dx.doi.org/10.32870/ \\ espiral.v24i68.6334
}

\section{Resumen}

Este artículo analiza algunos aspectos del surgimiento, de las formas de manifestación y de las implicaciones que el movimiento anticomunista tuvo en la vida política y social del estado de Jalisco en los años setenta. La trascendencia de este movimiento radica entre otras cosas en que su sede constituida en Guadalajara, capital del estado, se convirtió en el centro de operación más importante para América Latina. El presente artículo tiene como objetivo mostrar que el anticomunismo se solventó con la justificación de "proteger" a la sociedad de la "amenaza comunista" Ilamada "ola roja" ante la posibilidad latente de que se llevara a la práctica sociopolítica la ideología comunista en México y en América Latina, ya que el triunfo de la Revolución cubana era relativamente reciente. Por otra parte, se demuestra que puede considerarse el anticomunismo como un antimovimiento social, idea que se logró posicionar en el imaginario de la sociedad jalisciense y mexicana. Para la elaboración de este trabajo se utilizó la técnica de revisión documental en fuentes primarias del periodo.

Palabras clave: anticomunismo, Partido Comunista Mexicano, movilización social, antimovimiento social, Jalisco.

\author{
María Guadalupe Moreno González
}

Keywords: anti-communism, Partido Comunista Mexicano, social mobilization, social anti-movement, Jalisco.

-Profesora-Investigadora del Departamento de Estudios sobre Movimientos Sociales, CUCSH, Universidad de Guadalajara, México._magmg77@yahoo.com.mx

Fecha de recepción: 01 de junio de 2016. Fecha de aceptación: 18 de octubre de 2016. 


\section{Introducción}

El movimiento anticomunista en Jalisco es un fenómeno del que poco se ha escrito, esto a pesar de que fue una de las expresiones públicas más organizadas y de mayor envergadura que los grupos de derecha de la entidad y de México tuvieron en la década de los setenta en contra de toda manifestación de izquierda, pero principalmente de la izquierda partidista. En dicho movimiento se declaraba abiertamente la eliminación del comunismo en México y en Jalisco. Su principal forma de manifestación fue el ataque ideológico al Partido Comunista Mexicano, ataque que estuvo dirigido también a cualquier otra expresión de oposición al régimen.

El anticomunismo se define como la serie de expresiones, acciones y toma de posiciones políticas y sociales que la derecha planeó y organizó para frenar el desarrollo y permanencia del comunismo en el mundo, en México y en Jalisco.

Ubicar el contexto sociopolítico internacional en el que se desarrolló el movimiento anticomunista es indispensable para comprender en cierta forma su razón de ser. En ese sentido, el anticomunismo surgió en pleno periodo de la Guerra Fría, ${ }^{1}$ caracterizado por la tensión entre dos modos de producción social opuestos: el bloque del Este, identificado por el socialismo, ${ }^{2}$ liderado por la entonces Unión de Repúblicas Socialistas Soviéticas (URSS), y el bloque del Occidente, liderado por Estados Unidos y que proponía como ideal el desarrollo e implementación del capitalismo. ${ }^{3}$

I. Periodo internacional comprendido de 1945, al término de la Segunda Guerra Mundial, hasta el año de 1991.

2. Ideología cuya perspectiva general es la propiedad y la administración de los medios de producción por las clases trabajadoras con la intención de generar una sociedad sin clases sociales, y que tiene como objetivo la igualdad de la sociedad. 3. Ideología que tiene como objetivo la integración social y la redistribución de la riqueza, reconociendo como natural la desigualdad socioeconómica de las clases sociales y la propiedad de los medios de producción. 
Para el régimen capitalista, el socialismo y el comunismo en sus diversas expresiones y formas de organización fueron considerados como sus principales opositores y, por ende, como los adversarios a vencer.

En este contexto internacional, México se caracterizó por su sistema sociopolítico un tanto sui géneris, puesto que en materia de política exterior daba la imagen de ser un país democrático, en vías de desarrollo y solidario con las causas sociales y radicales que se vivían en otros países latinoamericanos, brindando, por ejemplo, asilo en más de una ocasión a refugiados políticos de países latinoamericanos (como el caso de Chile o Argentina), mientras que, en materia de política interior, se distinguía por tener un régimen autoritario y antidemocrático reflejado tanto en la hegemonía que ejercía el Partido Revolucionario Institucional (PRI) como la única fuerza posible por más de setenta años, como en la figura presidencial que representaba al Poder Ejecutivo, con un dominio sobredimensionado hacia los poderes Legislativo y Judicial, dominio reflejado en las decisiones verticales y unipersonales que el presidente de la república tomaba en casi todos los ámbitos de la vida del país, por ejemplo: la designación de los puestos y posiciones de los poderes Legislativo y Judicial en los ámbitos federal, estatal y municipal, la elección de su sucesor en la Presidencia, el manejo corporativo de los sindicatos de la clase trabajadora, la falta de libertad de expresión y la respuesta intolerante del Estado ante cualquier disidencia o crítica al régimen con la justificación de salvaguardar el orden y la estabilidad de las futuras generaciones, correspondiendo toda esta postura autoritaria en cierta medida con la doctrina de seguridad nacional que Estados Unidos promovió en el periodo de la Guerra Fría.

En otras palabras, México durante dicho periodo se definió como una sociedad en la que predominaba la hegemonía del PRI, partido que durante más de tres décadas contó con 
una oposición cómplice o sin fuerza alguna, y donde el presidencialismo se ejercía sin ninguna cortapisa, pues, como ya se ha dicho, el Poder Ejecutivo sometía al Legislativo y al Judicial (Santamarina Gómez, 1982).

Como respuesta a este contexto autoritario, se organizaron una serie de movilizaciones sociales y radicales no sólo de las clases sociales populares (obreros y campesinos), sino también de la clase media, de los estudiantes y los profesionistas de México. De esta manera, las movilizaciones de los años sesenta y setenta identificaron a una generación crítica del régimen capitalista y el sistema sociopolítico mexicano.

Jalisco no fue ajeno a la descripción antes señalada: si bien a la entidad se le ha etiquetado popularmente como un estado tradicional y sumamente conservador por su fuerte arraigo católico y sus Gobiernos con tendencia de derecha, también en la entidad se gestaron algunos de los proyectos más radicales de envergadura nacional que señalaron y lanzaron demandas en más de una ocasión al régimen sociopolítico imperante.

En este contexto es que surgió el movimiento anticomunista, identificado como una de las expresiones más definidas y públicas que la derecha y la ultraderecha desarrollaron en contra del comunismo y la izquierda en Jalisco, en México, en América Latina y en el mundo.

López Macedonio (2010), en un artículo sobre la historia del anticomunismo como una colaboración transnacional, afirma que

[en] la segunda mitad del siglo XX, en Asia y América Latina se fundaron organizaciones que armaron su identidad y su existencia en la lucha contra el comunismo [...]; en 1967, bajo la cobertura de la política anticomunista del Gobierno de Lyndon B. Johnson, fueron constituidas dos organizaciones que establecieron pactos de colaboración al comenzar la década de 1970. Una de ellas fue denominada Federación Mexicana Anticomunista de Occidente (FEMACO) y tuvo como sede permanente 
la ciudad de Guadalajara, Jalisco, México; la otra respondió al nombre de Liga Mundial Anticomunista (LMA) y la isla de Taiwán fue su base de operaciones (p. 134).

Con este antecedente, se precisa que el surgimiento del anticomunismo en Jalisco respondió a una lógica internacional más que a una nacional o local, como a su vez había sucedido con la lógica del Partido Comunista Mexicano (PCM), vinculado a la Internacional Comunista (IC) y al Partido Comunista de la Unión Soviética (PCUS).

Por ello, una de las principales justificaciones del movimiento anticomunista fue la de salvaguardar a la nación del "peligro" y de "la amenaza de la ola roja" que representaba para México el PCM.

El movimiento anticomunista en Guadalajara se desarrolló a través del grupo "Tecos" de la Universidad Autonóma de Guadalajara (UAG), identificado por Laura Romero como integrado por "activistas fascistas que dirigen no sólo el movimiento social sino a la UAG, ya que esta constituye la cortina que cubre sus actividades subversivas e ilegítimas" (Romero, 1986, p. 43).

El grupo tecos se identificó por el trabajo secreto que realizó a través de la Brigada Anticomunista de la Universidad Autónoma de Guadalajara (BADUAG). Romero (1986) señala que las prácticas de las sectas clandestinas relacionadas a un trabajo político contemplaban varias actividades como defensa personal, organización de grupos secretos con sus rituales definidos, vigilancia e instrucción militar, y sobre esto define que

La formación de militantes más comprometidos en las actividades subversivas incluye también la preparación militar cuyo propósito sería no sólo responder por la seguridad y el orden del propio movimiento, sino el de penetrar la ofensiva antimarxista. Dado que conciben que el marxismo es terrorista, le oponen un contra-terror antimarxista 
que se instrumentaría por los grupos de choque. Los integrantes de dichos grupos son entrenados por el Pentatlon, aunque también reciben armas, doctrina e instrucción en terrorismo por la organización Alpha 66 (Romero, 1986, p. 5I).

El anticomunismo realizó un trabajo continuo desde dos posiciones definidas: la ideológica, a través de campañas de desinformación, de desprestigio y del miedo e incertidumbre a lo que representaban el comunismo y la izquierda, y los hechos prácticos de persecución, de espionaje y de infiltración al PCM, hasta lograr la desaparición e invisibilidad de toda expresión comunista en la vida sociopolítica de la entidad.

Por ello, las principales acciones que el movimiento anticomunista desarrolló se hicieron en vinculación directa con los sectores más importantes de la derecha en la entidad, representados por el ya mencionado grupo "tecos" de la UAG -"la que constituye el centro a partir del cual se escuda y organiza ese movimiento que hace a Guadalajara la instancia fascista más importante no sólo de México, sino tal vez de América Latina” (Romero, 1986, p. 37)-, algunos grupos empresariales de la entidad, así como con las principales organizaciones gubernamentales encargadas de la seguridad nacional, como la Dirección Federal de Seguridad (DFS) y la Dirección de Investigaciones Políticas y Sociales (DIPS).

En ese sentido, uno de los objetivos de este documento es demostrar que el anticomunismo no fue un movimiento surgido de manera espontánea o aislada desde los grupos de la derecha de la entidad, sino que más bien respondió a una estrategia internacional que fue construida con antelación. Otro objetivo del presente trabajo es evidenciar la manera en que la primera universidad privada de la entidad, la UAG, se constituyó como el principal centro de operaciones del anticomunismo a nivel regional, nacional e internacional, y que su más importante medio de comunicación fue también 
su instrumento ideológico: la revista Réplica, editada de 1967 a 1987. Con todo esto, se pretenden explicar algunas de las implicaciones sociopolíticas de este movimiento o, mejor dicho, las que este antimovimiento tuvo para la izquierda de la entidad y para México.

\section{Elementos contextuales del anticomunismo}

Como ya se mencionó, internacionalmente en los años setenta se vivió el periodo de la llamada "Guerra Fría", definida por el enfrentamiento entre el capitalismo, representado por Estados Unidos, y el socialismo, representado por la Unión Soviética, y en América Latina (AL) como en el resto del mundo se evidenció la tensión entre estos dos bloques, ya que se tenía la experiencia del triunfo de la Revolución cubana, de 1959:

-tras una serie de resistencias y luchas civiles que se venían desarrollando en el país caribeño, desde 1953, por lograr su independencia de Estados Unidos-, con la expulsión del presidente Batista el régimen neocolonial se sustituye por uno de corte socialista, que hasta 1965 conformó el Comité Central del Partido Comunista de Cuba (PCC), máxima instancia de dirección de la revolución (Ecured, s/f).

Con este acontecimiento, existía la posibilidad de que en $\mathrm{AL}$ se modificaran los regímenes capitalistas y totalitarios, que habían llevado a la mayoría de los países a una polarización y a una pobreza exacerbada de su población, por regímenes comunistas o socialistas.

En AL, entre 1964 y 1984, a excepción de México, Cuba, Costa Rica y Venezuela, los países de la región estuvieron gobernados por regímenes militares ${ }^{4}$ totalitarios. A la vez,

4. Por ejemplo, en Argentina (1976- 1983), en Chile, con Augusto Pinochet (19731990), en Uruguay (1975-1985), y en Paraguay (1954-1989). 
se observó la organización de movimientos sociales y de movimientos armados que proponían al comunismo o al socialismo como la vía posible para el cambio de las condiciones sociales, económicas y políticas de vida.

Con respecto a este último punto, como respuesta a estas movilizaciones y a la expansión de la ola roja, ${ }^{5}$ en 1960 Estados Unidos implementó dos estrategias que impedían el desarrollo del bloque socialista en el continente:

- la doctrina de seguridad nacional, ${ }^{6}$ que mencionaba que las democracias occidentales no sólo estaban amenazadas por un enemigo externo expresado por el bloque socialista soviético, sino por un enemigo interno representado por los partidos, movimientos y líderes de pensamiento comunista-socialista. Por ello, esta doctrina justificó el desarrollo de una serie de estrategias de inteligencia y contrainteligencia para detectar y eliminar todos los elementos comunistas o socialistas del llamado "enemigo interno": ideologías, partidos, movimientos insurgentes y grupos radicales que elegían la vía revolucionaria, ${ }^{7}$ mismos que en su mayoría fueron reprimidos; $\mathrm{y}$

5. Nominación con la que popularmente fue conocido el desarrollo y expansión de la ideología socialista o comunista en el periodo de la Guerra Fría.

6. Para ampliar esta referencia, se sugiere revisar a Leal Buitrago (2003) ○ a Velázquez Rivera (2002).

7. Por ejemplo, en Nicaragua surgió el Frente Sandinista de Liberación Nacional (FSLN), en 1960, con orientación marxista; en Guatemala y El Salvador surgieron las Fuerzas Armadas Rebeldes (FAR) en los años sesenta, con orientación trotskista; en Chile surgió el Movimiento Izquierda Revolucionaria (MIR); en Colombia se estableció en 1965 el Ejército de Liberación Nacional (ELN), en 1965 las Fuerzas Armadas Revolucionarias de Colombia (FARC), de orientación leninista, y en 1968 el Ejército Popular de Liberación (EPL), de orientación marxista y de teología de la liberación; en Argentina surgieron los Montoneros, entre 1970 y 1979, movimiento identificado con ideología nacionalista y guevarista, y el Ejército Revolucionario del Pueblo (EPR), de 1970 a 1976, de ideología trotskista; en Perú, en 1970 1995, surgió el grupo Sendero Luminoso, identificado con ideología maoísta, y el Movimiento Revolucionario Túpac Amaru (MRTA), que existió entre 1984 y 2005, con orientación leninista; en Uruguay surgió el Movimiento de Liberación Nacional Tupamaros (MLNT), de 1964 a 1989, de rasgos marxistas; y en Bolivia, 
- la Alianza para el Progreso, ${ }^{8}$ aplicada en la región a través del Programa de Ayuda Económica a Gran Escala para los países en vías de desarrollo. Esta motivó el establecimiento de una serie de reformas socioeconómicas en los países latinoamericanos en materia de reforma agraria, alfabetización, desarrollo de libre comercio y programas sociales en materia de salud y vivienda, reformas que por las condiciones socioeconómicas de los países latinoamericanos no resultó complicado aplicar y que buscaban frenar el avance de la ideología de izquierda.

Además, en el transcurso de la segunda mitad del siglo XX, en Asia y América Latina se fundaron organizaciones que afirmaron su identidad y su existencia en la lucha contra el comunismo. Esas organizaciones trascendieron las fronteras de sus países de origen y crearon lazos cada vez más frecuentes a través de congresos internacionales anticomunistas realizados a lo largo del periodo (López Macedonio, 2010).

Mientras tanto, en México, durante el periodo presidencial de Gustavo Díaz Ordaz (1964-1970) existió cierta ambivalencia política del Gobierno federal. Por un lado, este sexenio se caracterizó por el fomento al crecimiento y desarrollo económico del país como una constante:

[...] en 1970 al concluir el sexenio de Díaz Ordaz, la inflación había sido de $2.6 \%$. El tipo de cambio era idéntico al de 1954: 12.50 [pesos] por dólar. Los aumentos salariales rebasaban el $6 \%$ anual en términos reales. El producto interno bruto, que había llegado a un II\% en 1964, creció uniformemente en el sexenio, llegando al 7\% promedio. [...] el

el "Che" Guevara apoyó a la organización del Ejército de Liberación Nacional (ELN), en 1966, con orientación marxista. Para ampliar estas referencias, se sugiere revisar: Gott (197I), Prieto (2007), Porto y Hocsman (2016), y Petras (20I3).

8. Para ampliar esta referencia, se sugiere revisar: Organización de Estados Americanos (1967). 
producto per cápita pasó de 300 dólares en 1958 a 700 en 1970; la deuda externa era de apenas 4263 millones de dólares (Krauze, 1999, p. 67).

Lo mismo sucedía con el reconocimiento internacional, llegando el país a ser la sede de los Juegos Olímpicos de 1968.

Por otro lado, se encuentra la intolerancia y la dureza con la que el Estado respondió a los movimientos sociales que se organizaron en este periodo presidencial.

En este sexenio se experimentó la máxima prueba del desgaste que el sistema político mexicano había alcanzado a dichas fechas con el poder sobredimensionado que ejercía el Ejecutivo sobre los poderes Legislativo y Judicial.

Prueba de esto fue el uso de la fuerza pública con que el Gobierno federal reprimió el movimiento estudiantil de 1968, gestado en la Universidad Nacional Autónoma de México y en el Instituto Politécnico Nacional, teniendo como punto máximo los acontecimientos del 02 de octubre de ese mismo año, cuando una manifestación pacífica de estudiantes en la Plaza de las Tres Culturas, en la Ciudad de México, fue reprimida, ocasionando una masacre (Montemayor, 2008, 2009, 2012).

De esta manera, la escala represiva organizada por grupos de ultraderecha y de derecha se constituyó lamentablemente en una práctica común que se dio de distintas formas y escalas en dicho sexenio: de la tortura física y psicológica, el espionaje político, la persecución, los crímenes y los secuestros, a la desaparición forzada, ${ }^{9}$ todo lo cual, entre otros hechos, fue la respuesta del Estado -y de organizaciones de derecha- a toda manifestación que cuestionara al sistema sociopolítico de la época y que tuviera simpatía con las ideologías comunistas o socialistas.

$\mathrm{Al}$ mismo tiempo, estas formas de represión fueron la prueba fehaciente del ya mencionado desgaste del sistema

9. Para ampliar esta referencia, se sugiere revisar: Comisión Nacional de Derechos Humanos (2009). 
político mexicano, que había estado identificado por el autoritarismo, la verticalidad de la figura presidencial y la intolerancia. Se presentaban entonces algunos síntomas inequívocos de agotamiento económico y social, reflejados en la agudización de su corporativismo, autoritarismo y prácticas antidemocráticas y represivas, el deterioro de la figura presidencial, así como en las movilizaciones que la sociedad civil organizó contra el régimen.

La década de 1970 en México también se caracterizó por la ambivalencia sociopolítica nacional e internacional. Por un lado, se tenía un ambiente de efervescencia política y social alimentado por las expresiones de izquierda ante la nueva ola de intelectuales europeos como Nicos Poulantzas, ${ }^{10}$ Louis Althusser ${ }^{11}$ y Herbert Marcuse, ${ }^{12}$ y la recuperación de Antonio Gramsci. ${ }^{13}$ Así mismo, la izquierda mexicana comenzaba a replantear y actualizar el legado del pensamiento marxista para América Latina a través de la crítica a los regímenes establecidos, que a su vez eran intolerantes, antidemocráticos y violentos hacia cualquier disidencia o cuestionamiento, por mínimo que este fuera. Por otro lado, el sistema político mexicano trataba de mantener la imagen de México como un país democrático y respetuoso de la libertad de expresión, siendo incluso huésped de oleadas de exiliados políticos extranjeros.

10. Filósofo y político de origen greco-francés, identificado como uno de los pensadores de mayor influencia en el pensamiento marxista estructuralista junto a Louis Althusser. Sus obras de mayor influencia fueron Poder político y clases sociales en el Estado capitalista, Las clases sociales en el capitalismo actual, Sobre el Estado capitalista, así como Fascismo y dictadura: la III Internacional frente al fascismo. I I. Filósofo marxista de origen francés. Entre sus obras más importantes están La revolución teórica de Marx y Para leer El Capital.

12. Pensador y filósofo judío. Entre sus principales obras se encuentran El hombre unidimensional, El marxismo soviético y Razón y revolución.

13. Filósofo y teórico marxista, escritor y periodista italiano. Están entre sus principales obras El materialismo histórico y la filosofia de Benedetto Croce, Odio a los indiferentes, así como Cuadernos de la cárcel/Prison notebooks. 
Por ejemplo, como lo han señalado Aguilar Camín y Meyer (1995), en el periodo presidencial de Luis Echeverría Álvarez (1970-1976), México se solidarizó con algunos países latinoamericanos que pasaban por situaciones adversas: dio asilo político a Hortensia Bussi, viuda del presidente de Chile Salvador Allende, en 1973, luego del golpe de Estado protagonizado por Augusto Pinochet, e hizo lo propio con un gran número de exiliados provenientes de las dictaduras de América del Sur.

Sin embargo, al interior de la república, el Gobierno de Echeverría se distinguió por continuar la intolerancia con los movimientos sociales y radicales que había caracterizado a la administración de Díaz Ordaz. De esta manera, en el primer lustro de los años sesenta se experimentó el aumento de la escala represiva por parte del Estado mexicano, pero también la organización social de diversos sectores de la sociedad en algunos estados de la república; las demandas inmediatas de estos eran comunes y exigían mejores condiciones de vida, libertad de expresión y de organización fuera del Estado, demandas que fueron expresadas en movimientos sociales y movilizaciones armadas o radicales. Entre los movimientos más relevantes se encuentran:

- La tendencia democrática de los trabajadores electricistas (Trejo Delarbre, 1978), que contaba con Rafael Galván entre sus protagonistas.

- El movimiento del magisterio, con el que Otón Salazar reivindicaría la autonomía organizativa y política, demanda también del movimiento médico de 1965 y el estudiantil de 1968 (Vocero Marxista de los Trabajadores y la Juventud, s/f).

- El movimiento estudiantil en la Universidad de Guadalajara (U. de G.) y el surgimiento del Frente Estudiantil Revolucionario (FER) como respuesta al monopolio que ejercía la Federación de Estudiantes de Guadalajara 
(FEG), vinculada con la derecha jalisciense (Tamayo Rodríguez y Moreno González, 2013).

- Grupos guerrilleros como la Liga Comunista 23 de Septiembre, la Unión del Pueblo y las Fuerzas Revolucionarias Armadas del Pueblo.

En consecuencia, las demandas de los movimientos sociales sectoriales y nacionales de las décadas de 1970 y 1980 expresaban la misma necesidad de autonomía organizativa y política. A su vez, un gran número de grupos optaron por la vía armada para transformar la sociedad, por ejemplo, a las guerrillas rurales de Guerrero se sumaron las urbanas en varios estados de la república, entre ellos Jalisco, Sinaloa, Nuevo León, Chihuahua, Sonora, Michoacán, Oaxaca, Hidalgo y la Ciudad de México (Gamiño Muñoz, 2006).

Lo ocurrido en Jalisco en 1968 fue un parte aguas, tanto para la Universidad de Guadalajara como para la izquierda local: se alimentó a las guerrillas, pero el grupo universitario fue reforzado por el Estado (De Dios Corona, 2004, p. 41).

Es importante hacer mención que para el anticomunismo toda acción o movilización social o radical era considerada acción comunista. El movimiento anticomunista adjudicó todas las expresiones radicales o de izquierda al PCM, lo que generó un imaginario social que magnificó los alcances del propio partido (Moreno González, 2016).

Al final del sexenio de Echeverría Álvarez se manifestó la presencia de movimientos radicales, entre ellos la Liga Comunista 23 de Septiembre (LC23s), las Fuerzas Revolucionarias Armadas del Pueblo (FRAP) y la Unión del Pueblo (UP). Para 1975, las denominadas guerrillas urbanas habían sido aniquiladas.

Fue precisamente en el par de sexenios hasta ahora mencionados (1964-1970 y 1970-1976) y la primera mitad del de José López Portillo (1976-1982) que se mostró la violencia aplastante del Estado contra la población civil. 
En la década de los sesenta, por ejemplo, la desaparición forzada de personas fue una práctica recurrente del Estado ejercida con planeación y sistematicidad; a pesar de esto, aún no se cuenta con el número preciso de personas desaparecidas y de presos políticos o perseguidos del movimiento anticomunista, aunque

entre 1969 y 1988, en el marco de la lucha contrainsurgente que desplegó el Estado mexicano en contra de movimientos insurgentes y organizaciones sociales, periodo conocido como "guerra sucia", las diversas organizaciones de familiares $y$ de derechos humanos registraron entre I 200 y I 800 desapariciones forzadas por motivos políticos (Desaparecidos 2, 2013).

Para 1976, al entregar Echeverría la Presidencia a López Portillo, se produjo una nueva devaluación de la moneda y, en consecuencia, se presentó una crisis nacional de grandes proporciones. En el terreno social y político, López Portillo, después de una violenta represión contra los grupos armados, buscaría conseguir cierta estabilidad deteniendo la llamada "guerra sucia" con el decreto de la liberación de los presos políticos mediante una ley de amnistía, y a través de la promoción de una reforma política que vería su realización en la promulgación de la Ley Federal de Organizaciones Políticas y Procesos Electorales (Krauze, 2002).

Este sexenio sería muy significativo para la vida interna del PCM: en 1977, con la reforma política nacional, el partido adquirió su registro oficial.

Aparejado con ello, se manifestaría la presencia abierta del anticomunismo y su proliferación a nivel internacional, siendo Guadalajara su sede de operaciones de México y de América Latina. Además, se vincularía directamente con la Liga Mundial Anticomunista (LMA), cuyo centro de operaciones estuvo en Taiwán. 
Romero (1986) evidenció la política internacional y nacional de lucha organizada contra la amenaza de la ola roja que, bajo la cobertura de la política anticomunista del Gobierno estadounidense de Lyndon B. Johnson, fue constituida por dos organizaciones que establecieron pactos de colaboración al comenzar la década de 1970: la Federación Mexicana Anticomunista de Occidente (FEMACO), en Guadalajara, ${ }^{14}$ y la ya mencionada LMA, en Taiwán.

De esta manera, en la vida política nacional y estatal se pudo ver claramente la coexistencia y tensión entre dos posiciones ideológicas: una que se guiaba por una serie de imaginarios reforzados por la derecha, la ultraderecha y el Estado, entre los que, por ejemplo, ser joven, estudiante y tener cabello largo era sinónimo de ser "sospechoso" o agitador social o comunista, y otra que criticaba la falta de libertad de expresión y de autonomía del Estado hacia la sociedad civil organizada.

\section{Jalisco y el anticomunismo}

Un aspecto que por mucho tiempo caracterizó a Jalisco fue su descripción como una de las entidades más conservadoras del país: el "común denominador de los gobernantes de Jalisco, de procurar que se conservara la tranquilidad y el orden, a efecto de fomentar el desarrollo con inversiones privadas, comerciales y de servicios" (Muriá, 2000, p. 189).

A esta descripción contribuyeron las presencias de grupos de ultraderecha-Opus Dei, jesuitas, legionarios de

14. Al constituirse, en 1967, adhirió a grupos como el Ateneo Anti-Marx, la Asociación Pro-Libertad Intelectual, la Unión Defensora de la Libre Empresa, la Fuerza Estudiantil de México, la Alianza Femenil Anticomunista, la Alianza Popular Anticomunista, el Bloque Estudiantil contra las Doctrinas Antinacionales, la Asociación Independiente de Comerciantes e Industriales, la Liga Defensora de la Empresa contra el Comunismo, la Delegación Anticomunista de Irapuato, la Unión de Estudiantes Católicos, Profesores Anticomunistas de Odontología, Derecho y Medicina, etc. (Romero, 1986, p. 52). 
Cristo, etc.- y de sectores de la sociedad civil que jugaron un papel importante en la vida política y económica, pues, para no perder el control local, la élite económica ocupó puestos públicos mediante procesos electorales; es decir, se generó un grupo de empresarios, funcionarios públicos y comerciantes que, desde una posición privilegiada y con vinculación al movimiento anticomunista, garantizaron el control político y económico de Jalisco.

Esta descripción de la entidad como "conservadora" convenía a los dirigentes del oficialismo local -funcionarios públicos, empresarios, líderes oficiales-y se contraponía con el surgimiento de una serie de movimientos más radicales en el país, como el movimiento médico o el movimiento magisterial.

Por ejemplo, en 1968 Jalisco se había caracterizado por ser una de las pocas entidades que no se había solidarizado con el movimiento estudiantil nacional. La explicación de esto reside precisamente en la vinculación de la organización estudiantil de la U. de G., denominada Federación de Estudiantes de Guadalajara (FEG), con los Gobiernos federal y estatal, puesto que al inicio del movimiento estudiantil el Gobierno "[...] requirió de sus servicios y le proporcionó armas de alto poder para reprimir el descontento que comenzaba a manifestarse entre el estudiantado" (Gil Olivo, 2008, p. 552).

Por otro lado, el PCM en Jalisco fue una de la expresiones de izquierda partidista de más larga duración en la vida política y social del estado (su existencia data de alrededor de 1926 y se prolonga hasta 1981), y para la segunda mitad del siglo XX el partido se caracterizó, entre otras cosas, por su fuerte vinculación con diferentes sectores sociales (obreros, campesinos, universitarios y profesionistas) y por su presencia en las principales luchas y resistencias sociales del estado, lo que lo hizo constituirse como el principal objetivo de ataque del movimiento anticomunista. 
Por su parte, una de las particularidades del movimiento anticomunista fue que, como ya se ha señalado antes, de manera errónea identificó a todas las acciones de oposición al régimen como comunistas y con relación directa al PCM, a tal grado de catalogar al partido mismo como una amenaza para la sociedad: "sin duda los imaginarios de la amenaza de la ola roja y el peligro de las sociedades democráticas y libres trascendieron más allá, en acciones concretas de persecución y desaparición de militantes comunistas y de otras izquierdas" (Moreno González, 2016, p. 181). El movimiento anticomunista hacía esto sin diferenciar las diversas expresiones que en la época existían de los grupos autodenominados de izquierda que no se identificaban necesariamente con el partido. Por su parte, las autoridades federales y estatales vinculaban toda forma de manifestación en contra del régimen como acciones comunistas, y la represión se ejerció de manera general y sumamente violenta.

Ante el escenario descrito, el PCM tuvo al movimiento anticomunista nacional e internacional como su principal enemigo. Como ya se dijo antes, el movimiento se habría desarrollado en la UAG, y más concretamente a través de su grupo denominado "los tecos", también ya señalado en la introducción de este trabajo. Sobre esta organización se tienen varias versiones. Por ejemplo, para Laura Romero, los tecos formaron parte de la amplia oposición católica que había combatido el proyecto de nación impulsado por los Gobiernos emanados de la Revolución mexicana. De esta forma,

El 16 de julio de 1967 surge la organización que da cobertura al movimiento teco en sus diferentes instancias. La Federación Mexicana Anticomnista, FEMACO, se origina "para hacer frente a los ataques comunistas salvaguardando nuestras familias, nuestras personas y contribuyendo a 
librar a México de la esclavitud infrahumana del comunismo" (Romero, 1986, p. 42). ${ }^{15}$

Prueba de esto fue la declaración que públicamente hizo la FEMACO el 29 de septiembre de 1968 en el diario jalisciense El Informador, en plena efervescencia del movimiento estudiantil en México que, como se ha comentado, se caracterizó por su represión violenta por parte del Estado:

el terrorismo[,] del que la guerrilla urbana es un pálido principio, tiene una importancia básica en el proceso de comunicación de un país. Más aún, el terrorismo es una institución intrínseca del comunismo. Actúa contra el hombre y contra la colectividad para hacerles perder su voluntad, para trastornar su personalidad, para convertirlos en un sujeto maleable que obre en contra de sus aspiraciones más profundas. La inclinación humana hacia el bien, la verdad y la dignidad se convierten[,] por obra del terror, en la aceptación de la mentira, el odio y el crimen (El Informador, 1968, p. 8-A).

Otra versión sobre los tecos es la que refiere Enrique Maza en una entrevista realizada al "Lobo", un médico miembro del Ejército de Liberación Anticomunista, publicada en la revista Proceso en 1986 y en la que se refiere a estos como

una sociedad secreta llamada los tecos. Los tecos, virulentos anticomunistas y antisemitas, tienen control sobre muchos estudiantes y profesores. Obligan a juramentos de lealtad y operan su propia red de espionaje en el campus universitario. El profesor Raimundo Guerrero enseñó en la universidad: era el jefe de FEMACO y el presidente de la CAL [Confederación Anticomunista Latinoamericana]. Los escuadrones de la muerte de la CAL. Los escuadrones de la muerte en América Latina operan en coordinación a través del cuerpo central, la CAL (Maza, 1986).

I5. Las comillas incluidas en la cita son del original. 
Si bien a esta organización se le ha denominado como una fraternidad o bien un grupo neonazi que organizaba escuadrones de la muerte, para este documento lo más importante es su relación con la FEMACO.

No obstante, debe agregarse respecto a los tecos que hacia la década de 1970 la Brigada Anticomunista de la Universidad Autónoma de Guadalajara (BADUAG), a través de la cual operaba, seguía teniendo una serie de prácticas propias de sectas clandestinas, como el llamado "ceremonial de sesiones", que reflejaba el activismo anticomunista de la ultraderecha jalisciense (Romero, 1986, p. 49).

Uno de los principales instrumentos ideológicos que utilizó el movimiento anticomunista como medio de comunicación, y que se constituyó, en cierta forma, en la prueba más fehaciente de este movimiento, fue la revista llamada Réplica. Esta se autodefinía como "una revista mensual que trata los problemas que el comunismo internacional plantea a los hombres libres [...] es la respuesta a la conspiración que atenta contra los valores más preciados de nuestro pueblo: su libertad, su independencia” (Revista Réplica, 1967a, p. 1).

Esta revista fue editada desde el 01 de noviembre de 1967 al mes de enero de 1987, es decir, durante casi veinte años, a lo largo de los cuales se editaron doscientos cuatro números. Evidentemente, la publicación de la revista coincide con los procesos de radicalización de los bloques capitalista y socialista de la Guerra Fría en América Latina, y su desaparición fue justo dos años antes de la caída del bloque socialista -y con ello del fin de la Guerra Fría-.

El tiraje de la revista se específica en el número quince, volumen dos de Réplica, en el que se menciona que "tiene actualmente un tiraje de cinco mil ejemplares que se venden a tres pesos cada uno" (Revista Réplica, 1969b, p. 1). Con esta cantidad de tiraje se precisa el tamaño y la dimensión de su aceptación e influencia en diversos sectores locales, 
nacionales e internacionales; vale hacer la aclaración de que la cantidad del tiraje no fue incluida en otro número de la revista, no así el costo de la misma, que se siguió indicando.

A partir de abril de 1972, se estableció una leyenda en cada número en la que se señala que la revista "está autorizada como correspondencia de segunda clase por la Dirección General de Correos en oficio 2151-13559, expediente 091.70/881 del 11 de abril de 1972”.

Desde su primer número, la revista respondía a la interrogante sobre su título con la pregunta “¿qué es Réplica?”. De manera fehaciente, en la primera página del primer número se señala el origen de su nombre:

Réplica a la conjura internacional que hipócritamente predica la paz y la autodeterminación de los pueblos, mientras practica el más descarado intervencionismo, e impunemente arma y dirige grupos de asesinos a sueldo para que maten campesinos indefensos en las llamadas luchas de guerrillas. Réplica a la mentira y la confusión sembrada por intelectuales de café, siempre dispuestos a unirse al coro de comparsas del comunismo a cambio de elogios comprometidos y subsidios de embajadas (Revista Réplica, 1967a, p. I).

Así mismo, se señalaba el objetivo de la revista: ser "una publicación mensual destinada al pueblo, que tiene como propósito ofrecer informaciones y comentarios sobre la agresión comunista contra la humanidad" (Revista Réplica, 1967a, p. 1).

Para 1972, Réplica se autodefinió como "una revista sin publicidad, que se edita con el propósito de señalar las amenazas del comunismo contra la nación y contra la humanidad" (Revista Réplica, 1972a, p. 1).

A partir del número cincuenta y seis se recrudeció el propósito de la revista en la descripción de su postura, al referir lo siguiente: 
En respuesta a las numerosas peticiones recibidas en la Dirección de esta revista, hacemos del conocimiento de nuestros lectores, corresponsables y amigos que tenemos un especial interés en divulgar, lo más extensamente posible, nuestra permanente denuncia de las falacias y crímenes del Comunismo Internacional así como la insidiosa y traidora labor de sus cómplices y aliados (Revista Réplica, 1974c, p. I).

Esta redacción fue firmada por el director de la revista, con énfasis en la autorización para su reproducción, siempre y cuando se diera crédito a la publicación original y se enviara a Réplica prueba de la reproducción.

El equipo responsable de producción estuvo integrado en 1967 por seis miembros:

Director, José Chávez Chávez; jefe de redacción, Salvador Cervantes C.; circulación, Jorge Paredes Tirado; y por los redactores: Sergio Lastra R., Antonio Durán U., Arturo Martínez O. y Oscar Dena R. [Su correspondencia se enviaba a] Réplica, en Av. Vallarta 1525-302, en Guadalajara, Jalisco (Revista Réplica, 1967a, p. I).

Estos miembros formaron parte del volumen uno, que incluyó los números uno a ocho y que finalizó en agosto de 1968. A partir del número nueve se estableció el volumen dos, esto en octubre de 1968, y el equipo editorial se amplió de la siguiente forma:

Director: José Chávez Chávez; jefe de redacción: Oscar Dena; colaboradores: Jorge Prieto Laurens, Aduard Saj, Arturo Martínez Ortega, Salvador Cervantes, Antonio Duran, Gonzalo E. Vargas, Diego Marco, Ernesto del Castillo y Raymundo Guerrero [que llegó a ejercer un liderazgo importante en Jalisco, en América Latina y en el mundo, puesto que fue el secretario general de la ya mencionada LMA, en Taiwán] (Revista Réplica, 1968, p. I). 
Además, se sumaron servicios internacionales de prensa que estuvieron presentes hasta el último número: "Aginter Presse, Fuerza Nueva, China News, WACL, Centro Iberoamericano de Documentación Europea, Oltremare. Corresponsalías en centro y sud América [sic]. Circulación: Jorge Paredes. Redactores: Guillermo Fernpandez, Jorge Bonilla, Luis Vega Díaz y Miguel Verduzco" (Revista Réplica, 1968, p. 1).

A partir del número catorce, de junio de 1969, la revista tuvo como director a Sergio Américo Lastra y como jefe de redacción a Oscar Dena, pasando como colaboradores el anterior director José Chávez Chávez y Salvador Cervantes, además de crecer este grupo con la participación de "Rene Capistran Garza, Margarita Michelena, Rafael Rodríguez, Santiago Illescas, Javier Riera" (Revista Réplica, 1969a, p. 1).

A partir del número cincuenta y seis, el director de la revista volvió a ser José Chávez Chávez, identificando una estructura más formal con las figuras de editor (Pablo Huerta Gaytan) y de gerente (Ramón Rodríguez) (Revista Réplica, 1974c, p.1).

Otro ejemplo es el incremento de los servicios internacionales de prensa, a los que a partir del número treinta y nueve, del volumen dos, con fecha de octubre de 1972, se agregaron "Asian Outlook, Bulletin, Vietnam Magazine, Le Service d'intelligence Canadien, Crítica Católica, América Latina \& Studies" (Revista Réplica, 1972a, p. 1).

A partir del número cuarenta, editado en noviembre de 1972, la revista dejó de tener volúmenes (se conservó la numeración sin ellos, no obstante) y sus oficinas cambiaron de dirección a Av. Las Américas 132, en la misma ciudad de Guadalajara, Jalisco.

Con respecto al contenido, en el número dos se señalan de manera directa los ataques al comunismo y, en cierta forma, la directriz que debía tomar esta revista. Con esto se 
evidencia el carácter de esta como instrumento ideológico, al señalar entre otras cosas que

[...] Conclusión: Los regímenes comunistas lejos de disolver las clases sociales, son ahora aquellos donde la diferencia es más marcada [...]. Conclusión: la historia de que el comunismo ha realizado una planificación nacional de su economía, es la más grande mentira de los últimos 2000 años. El comunismo sí industrializó a Rusia, pero sin ninguna superioridad en aspecto alguno, excepto en el precio pagado con sufrimientos humanos, industrializando a los grupos sin emancipar al individuo. El comunismo realiza en la historia, una función contrarevolucionaria (Revista Réplica, 1967b, pp. 32-33).

Con este ejemplo, se señala el carácter con el que la revista guio el desarrollo de sus doscientos dos números subsecuentes. En cada uno de sus números se hizo explícito el objetivo central del movimiento anticomunista: la desaparición de toda manifestación comunista nacional e internacional, identificando al PCM como el enemigo a vencer.

Por ello, además del PCM, la U. de G. se constituyó en otro referente obligado del anticomunismo, dado que en su propia ideología la universidad se definía como "socialista", ${ }^{16}$ a pesar de que su organización estudiantil, la FEG -que no representaba a la mayoría del estudiantado de la institución- mantenía, como se ha mencionado, una vinculación directa con los Gobiernos estatal y federal y era considerada como el principal órgano de contención y control de cualquier posición radical o crítica al régimen. Es importante aclarar que no se estableció una vinculación de la FEG con la UAG, sólo, como ya se ha dicho, con los Gobiernos federal y estatal.

16. De hecho, la fundación de la Universidad Autónoma de Guadalajara se dio precisamente por la escisión de un grupo ante el conflicto universitario que hubo en 1935, cuando en la Universidad de Guadalajara se promulgó la reforma universitaria que estableció la educación socialista en su interior (Romero, 1988; Dorantes, 1993). 
Esta lógica de ataque a cualquier manifestación de disidencia al régimen en México evidencia los dos frentes que estuvieron presentes para contener la llamada "amenaza de la ola roja” que como ya se señaló Estados Unidos había definido en su doctrina de seguridad nacional: por un lado se identifica un frente en el Estado mexicano, que justificaba el uso de la fuerza y la desaparición forzada para reprimir cualquier manifestación que considerara disidente del régimen, bien fuera pacífica o radical, y por otro lado se identifica otro frente en el movimiento anticomunista, que desde lo ideológico y con algunas prácticas subversivas creó un imaginario social de rechazo hacia el comunismo o el socialismo, no sólo en la entidad, sino a nivel nacional e internacional. Réplica sería entonces la publicación clave de difusión de este imaginario.

Por ejemplo, en agosto de 1973, en el sexto aniversario de la revista, bajo el encabezado "Luchando por México" se señala:

Hace seis años cuando celebrábamos en Guadalajara el Congreso fundacional de la FEMACO, nos habíamos fijado como meta, los que desde entonces nos entregamos en ella, bajo la dirección y jefatura del Lic. Raimundo Guerrero, el llevar nuestro mensaje anticomunista a todos los rincones de la patria para alertar a la sociedad mexicana frente a actuación cada vez más intensa y efectiva de los grupos comunistas en nuestro país. Se reunieron centenares de personas que militan en los diferentes organismos especializados afiliados a la FEMACO, como son la Asociación Pro libertad Intelectual (APLI), Alianza Femenil Anticomunista (AFA), Fuerza Estudiantil de México (FEM), el Ateneo Antimarx, la Alianza Popular Anticomunista (APA), y el Grupo Empresarial Anticomunista. En los diversos organismos se han integrado estudiantes, intelectuales, maestros, profesionistas, amas de casa, empleados, obreros, campesinos y hombres de empresa que entusiasmadamente desarrollan actividades anticomunistas en el país (Revista Réplica, 1973a, p. I). 
Para entonces, el anticomunismo que permeaba la vida política y social de la entidad era evidente para toda la sociedad:

[...] los diarios más difundidos en la ciudad expresaban su fobia ideológica en contra de todo aquello que no era acorde con sus posturas. Un ejemplo de ello fue el caso del maestro José Parres Arias, que fue acusado de "envilecer y deshonrar" a la Universidad de Guadalajara por emplear libros de texto de orientación marxista en la educación media superior. El diario El Occidental en sus distintas editoriales de los años cuarenta presionó a las autoridades universitarias para que fuera destituido de su cargo; pero no logró su propósito (Tamayo Rodríguez y Moreno González, 2013, p. 309).

Estos años fueron particularmente difíciles para la U. de G.: por un lado, contó con la presencia de profesores exiliados políticos que compartían el ideal comunista o socialista, fomentaban la libertad de expresión y la lucha por la democracia, mientras que, por otro lado, se contaba con la organización de células comunistas del PCM en diferentes escuelas y facultades de la universidad, se afiliaban estudiantes a las Juventudes Comunistas y existían otros grupos radicales no afiliados precisamente al PCM, entre ellos el FER, y otros grupos de izquierda. Por todo ello,

los estudiantes de la UAG continuaron con su agresividad en contra de la Universidad de Guadalajara, afirmando que era un bastión del ateísmo y el comunismo, a quien era necesario reducir a fin de conservar la patria, la religión, la propiedad, la moral y la libertad (Tamayo Rodríguez y Moreno González, 2013, p. 310).

Después de la represión de 1968, varios grupos de izquierda universitaria iniciaron un proceso de organización que dio pie, en 1970, a la creación del FER (entrevista personal, 2008). Su primera acción fue tomar la Casa del Estudiante, que había sido el local de reunión y operación de la para 
entonces extinta Federación de Estudiantes de Occidente (FESO).

El FER fue conformado por diversos grupos universitarios y estudiantiles de izquierda, entre ellos los Vikingos de San Andrés y las Juventudes Comunistas (JC); la mayoría de sus integrantes eran pequeñas agrupaciones. El FER se convirtió en el principal grupo antagónico de la FEG (Tamayo Rodríguez y Moreno González, 2013).

El enfrentamiento entre el FER y la FEG se extendió durante todo el año de 1971 y provocó muertes de ambas partes y decenas de detenidos (curiosamente todos del FER y ninguno de la FEG -entrevista personal, 2007-).

El FER, orillado por las circunstancias y en la clandestinidad, se enfrentó a la FEG y a las fuerzas policíacas. Además, en su seno había agentes del llamado "servicio secreto" que se habían hecho pasar por estudiantes, y ello en cierta forma incidió en su desaparición (Robles Garnica, 2013). Posteriormente, en 1973, nació la LC23s, y con ella se desencadenaría la guerrilla urbana en la entidad (Carrasco Gutiérrez, 1999; Morales Hernández, 2007).

El Gobierno federal respondió al enfrentamiento entre la FER y la FEG respaldando a esta última, puesto que "ni el presidente Díaz Ordaz y ni Echeverría Álvarez olvidaron que eran deudores de los buenos servicios de esa 'mafia' en la represión de 1968 y que la U. de G. había sido la única del país que mantuvo las puertas abiertas" (Gil Olivo, 2008, p. 552), por lo que esta organización estudiantil "gozaba del apoyo estatal, este [el Estado] le entregaba armas, les brindaba legitimidad, apoyo político y por ende impunidad. Esta protección, apoyo y cercanía con el Gobierno estatal fue utilizada por algunos miembros de la FEG como trampolín político" (Gamiño Muñoz y Toledo González, 2011, p. 19). Esto ocasionó la represión con fuerza aplastante del FER y, por supuesto, la represión a las juventudes comunistas y al propio PCM. Estas manifestaciones evidentemente son el 
ejemplo más significativo de las dos vías del anticomunismo: la ideológica y la acción directa del Estado.

Conforme el Estado aplicaba estos actos represivos, el movimiento anticomunista hacía su propia tarea de difusión: el número cincuenta y tres de Réplica señaló, bajo el encabezado "La maquinaria comunista", que

El aparato comunista es una combinación de estructuras secretas y abiertas (FER y Comité de Lucha del Poli), por ejemplo, de aparatos militares y políticos (Partido de los pobres y la Brigada Campesina de Ajusticiamiento), de instituciones de masas y "frentes" (Comité de Defensa Popular de Chihuahua y Movimiento Mexicano por la Paz o Movimiento de Cristianos por el Socialismo) [...]. Volviendo al tema. Estas organizaciones de masas, secretas y públicas, tratan de involucrar a todo mundo dentro de una comunidad. Basta recordar en la ciudad de Guadalajara cuando políticos inescrupulosos se acercaron a las pandillas de jóvenes que habitaban por la colonia de San Andrés, conocidos como los "vikingos". Primero les dieron dinero, poco a poco los iniciaron en las drogas, regalándoles mariguana, y cuando los tuvieron sometidos por el vicio los comprometieron en delitos menores para que ya no pudieran escapar de la red que les rodeaba (Revista Réplica, 1973b, pp. 16-17).

Sin duda, con esta aseveración se demuestra, por un lado, el conocimiento de los hechos que acontecían en la vida política de la ciudad, pero también, por otro lado, la información sesgada de los hechos. Como un ejemplo de ello, se incluye aquí el esquema contenido en el número cincuenta y tres de Réplica, un esquema muy ilustrador sobre el reconocimiento de los actores en plena efervescencia de la LC23S (ver Imagen 1). 
Imagen 1. Diagrama "Aparato subversivo comunista en México"

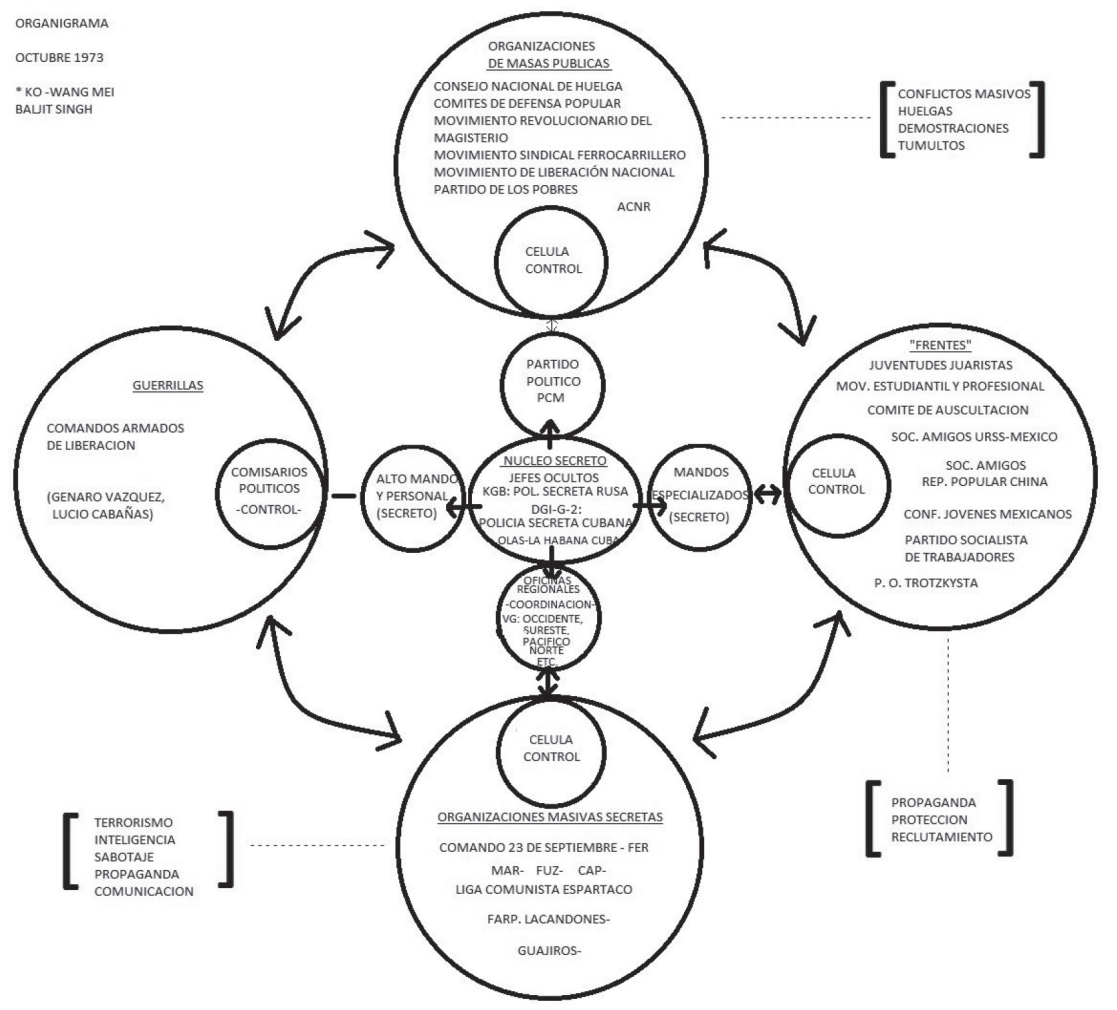

Fuente: Revista Réplica (1973b, p. 21).

Con este esquema se evidencia el conocimiento y la interpretación que les interesaba difundir en la revista.

Volviendo a la acción del Estado, el acoso policiaco no disminuyó sino hasta 1976, año en que el PCM solicitó oficialmente su registro como partido político y en que se postuló por el mismo de manera abierta y pública como candidato a la Presidencia de la república al líder ferrocarrilero Valentín Campa (De Dios Corona, 2004, p. 50). 
Mientras tanto, respecto a la estrategia ideológica, un acto importante que se realizó desde los años setenta hasta principios de los años ochenta consistió en el reparto de calcomanías con la leyenda: "Este hogar es católico y no se acepta propaganda protestante o comunista", calcomanías que era común encontrar en las puertas o ventanas de los hogares de colonias populares de Guadalajara. ${ }^{17}$

En la leyenda de estas calcomanías se identifica la confusión que creaba el anticomunismo contra el partido y con la magnificación de sus acciones, ya que se equiparaba a la ideología protestante con la de un partido de izquierda. La implicación, entonces, de algunos grupos de la Iglesia católica fue clave para generar un imaginario social negativo y de rechazo a todo lo que fuera comunista o socialista.

Por ello, la represión y el hostigamiento del anticomunismo al PCM llevaron al partido a ciertos periodos de clandestinidad, con lo cual se vivió un serio repliegue del partido de la sociedad y una práctica común: el expulsar a algunos de sus miembros, dado que la infiltración y el espionaje eranprácticas comunes del anticomunismo hacia el partido.

Como una respuesta ante los embates del anticomunismo, el PCM hizo un comunicado público en uno de los diarios más consultados de la época (ver Imagen 2).

Este desplegado fue firmado por diecinueve organizaciones, entre ellas la Comisión Nacional Juvenil del PCM.

17. De estos volantes no se ha encontrado rastro respecto a su origen, ni en el archivo del Arzobispado de Guadalajara ni en el Archivo Histórico de Jalisco ni en la revista Réplica; sin embargo, aún es común encontrar estas calcomanías en puertas o ventanas de hogares de las clases medias y bajas de Guadalajara. 


\section{Imagen 2. Comunicado del PCM}

Son también conocidas las frecuentes agresiones que se han cometido contra maestros y estudiantes de la Universidad de Guadalajara, así como a miembros de la Federación de Estudiantes de Guadalajara. Además, han sido dañados instalaciones y bienes de dicha Universidad.

Su alianza con organismos de la subversión y espionaje norteamericanos es evidente. De todos es conocido que la UAG recibe jugosos subsidios de las Instituciones yanquis que conspiran contra la estabilidad política y económica de nuestro país (Fundación Ford, Fundación John Birch Society, Fundación Rockefeller, la Universidad de Michigan y otras que sería largo de enumerar).

La naturaleza claramente pro-fascista de la UAG, ha engendrado que en su seno se formen y adiestren grupos paramilitares, guardias blancas e individuos delictuosos que, amparados en la supuesta "autonomía" de la institución se dedican a actividades de espionaje al servicio de una potencia política y militar extranjera, concretamente los Estados Unidos de Norteamérica.

Su actitud fascista está ampliamente demostrada por las frecuentes declaraciones de elogio al fascismo que se hace en las páginas de su órgano informativo, de la revista "Répli-

Fuente: El Informador (1977b, p. 1-A).

En otra nota periodística publicada también en El Informador se evidencia otra serie de grupos anticomunistas que actuaban "por el bien de Jalisco y del mundo ante el embate de los comunistas" (El Informador, 1977a, p. 11-A). La nota también es prueba de ese imaginario que se construyó alrededor del comunismo:

Para hacer frente a los ataques comunistas salvaguardando nuestras familias, nuestras personas y contribuyendo a librar a México de la esclavitud infrahumana del comunismo, hemos tenido que organizar, documentar, cohesionar y poner a trabajar a jóvenes especialmente; pero también a numerosos adultos, hombres y mujeres en asociaciones afiliadas a la FEMACO, tales como el Ateneo Anti-Marx, la Asociación Pro-Libertad Intelectual, la Unión Defensora de la Libre Empresa, Fuerza Estudiantil de México, Alianza Femenil Anticomunista, Alianza Popular Anticomunista y otras que con su esfuerzo particular sufragan la actividad anticomunista (El Informador, 1977a, p. II-A).

Sin duda, la organización de diversos grupos de ultraderecha contra los imaginarios de la amenaza de la "ola roja" y el peligro de las sociedades democráticas y libres trascendió en acciones concretas de persecución y desaparición de militantes comunistas. 
En cierta forma, este testimonio forma parte de las campañas abiertas que se dirigían a la población de Jalisco, y que a través de la desinformación sobre el comunismo se legitimaban en bien de la sociedad para ejercer la represión sobre los comunistas. En el interior de estos grupos probablemente se establecían códigos aún más excluyentes $\mathrm{y}$ violentos sobre el comunismo.

En ese sentido, el Partido Comunista tuvo a un enemigo más sofisticado que las simples confrontaciones políticaspoliciacas del contexto jalisciense. Se trataba más bien de toda una organización anticomunista con dimensión internacional.

Hablando, por ejemplo, de la FEMACO, sus alcances no sólo fueron a nivel nacional: incluso en Latinoamérica, con la creación de la CAL, tuvo una participación clave, como se evidencia en el cierre del II Congreso de la CAL, desarrollado en enero de 1974 en Río de Janeiro:

El Prof. Raimundo Guerrero, Presidente de la Liga Mundial Anticomunista y Presidente de la FEMACO, fue el invitado de honor del Congreso, y participó de las reuniones más importantes. De su conceptuoso discurso entresacamos: "A un año y meses de haber fundado en México la Confederación Anticomunista Latinoamericana nos es dable presenciar ya sus importantes realizaciones, sin precedente inmediato en cuanto a esa 'práxis' anticomunista tan efectiva que ha venido a romper ciertos patrones teorizantes y retóricos, en que están reincidiendo algunos anticomunistas". [...] Contra Los Comunistas: "Redoblaremos Nuestros Esfuerzos por Denunciarlos, y por Desenmascararlos y por Combatirlos a los Ojos Del Mundo y de la Historia" (Revista Réplica, 1974a, pp. 5-6).

En este II Congreso se estableció la agenda de trabajo de la confederación, en la cual se señalaban las principales actividades y comisiones encaminadas a reforzar el movimiento (o antimovimiento) a nivel internacional. Réplica aparece de nuevo difundiendo el mensaje, esta vez en su 
número cincuenta y cinco: "a ella [al Congreso] asistieron 205 delegados de toda América Latina, representando a más de 70 organizaciones y entidades miembros de la CAL y 19 naciones representadas: Argentina, Bolivia, Brasil, Colombia, Costa Rica, Cuba en el exilio, Chile, Ecuador, El Salvador, Guatemala, Honduras, México, Nicaragua, Panamá, Paraguay, Perú, República Dominicana, Uruguay y Venezuela” (Revista Réplica, 1974b, pp. 8-11).

Con ello se demuestra el alcance y la organización que la CAL tenía a unos años de su creación en buena parte del continente, y cómo la UAG, con revista y personal de por medio (Raimundo Guerrero, ya se ha dicho, era funcionario de la universidad), funcionó como su principal centro de operaciones.

Otra de estas organizaciones operadoras del anticomunismo fue la Liga Mundial Juvenil Anticomunista (LIMJA), que en enero de 1974 se reunió en la ciudad de Guadalajara, a sólo unos meses de llevar a cabo su quinto congreso en la ciudad de Washington (Revista Réplica, 1974b, p. 36).

Es oportuno mencionar que un año después del nacimiento de la formación de la CAL, Latinoamérica fue abatida por una ola de represiones, desapariciones y torturas que no cesó hasta finalizar la década de 1980 (Paredes, 2004).

Estas acciones, nombradas "Operación Cóndor", fueron definidas como un pacto de colaboración sistemática entre las dictaduras militares sudamericanas y los servicios secretos de inteligencia de Estados Unidos para recoger e intercambiar información y emprender operaciones de ejecución, secuestro y extradición clandestina de las izquierdas políticas latinoamericanas (Paredes, 2004).

Ante esta expansión del movimiento, queda la duda sobre quién y cómo financiaban sus actividades la FEMACO, la CAL y las demás organizaciones, puesto que se tenía una vida intensa de acciones internacionales, nacionales y locales. $\mathrm{Al}$ 
respecto, se tienen algunos señalamientos de que Estados Unidos financiaba las actividades de estas organizaciones:

En 1960, la UAG tenía un presupuesto de 50000 dólares. En 1975, lo tenía de 10 millones de dólares El vicerrector Antonio Leaño, alto dirigente teco, calificó el hecho como "un milagro de la filantropia estadunidense y mexicana".

El milagro fue resultado de los fondos proporcionados por el Gobierno de Estados Unidos a través de la AID y de las fundaciones filantrópicas estadunidenses. Entre 1964 y 1974 regalaron 20 millones de dólares a la universidad de los tecos, a pesar de todos los ataques tecos a los Estados Unidos, a los que unían con el judaísmo y con la Iglesia del Vaticano II.

Con la ayuda financiera de Estados Unidos, los tecos pudieron financiar sus programas no precisamente académicos. La universidad sirvió para lavar el dinero. Sus actividades políticas son muchas. Además de sus relaciones neonazis con Europa y América Latina, ahora tienen fondos para crear grupos políticos de fechada, como la FEMACO y la Confederación Interamericana de Defensa Continental, que sirve de enlace con los escuadrones de la muerte. Entraron a formar parte de la Liga en 1972 (Maza, 1986).

Sin duda, se requirió de un apoyo económico significativo para desarrollar las estrategias planteadas en el movimiento. De confirmarse este supuesto, la doctrina de seguridad nacional implementada por Estados Unidos resultaría un factor clave.

Con relación a la afirmación que se ha realizado casi al principio de este documento, sobre si se puede señalar al movimiento anticomunista como un antimovimiento social, esto es factible desde la perspectiva que toma Alain Touraine (1997) en su respectivo análisis sobre las formas de antimovimientos sociales como respuesta o transformación de los movimientos societales (como los movimientos históricos y culturales), en tanto "los antimovimientos sociales 
aparecen también en los países democráticos. En estos casos, apelan a la tradición nacional amenazada por la invasión de poblaciones o de costumbres extranjeras" (p. 125). Entonces puede decirse que el anticomunismo encaja en esta definición, al menos con respecto a las acciones específicas del PCM, que en esencia buscaban la justicia, la igualdad y la inclusión de sectores vulnerados por el capitalismo.

Una precisión que hace Romero (1986) es que el sistema político postrevolucionario no se planteó como eje esta política anticomunista, sino que fue una acción organizada por organismos civiles; sin embargo, tampoco se constituyó como el árbitro responsable de proporcionar las garantías sociales tanto a los militantes comunistas mexicanos como a cualquier otro ciudadano mexicano, sino que más bien actúo de manera paralela al objetivo de erradicar toda amenaza al régimen sociopolítico.

$\mathrm{Al}$ respecto, a partir de la década de 1970 fue más claro el rechazo y el imaginario social negativo que sembró Réplica entre la población hacia el PCM, los universitarios de la U. de G. y los militantes de izquierda, al relacionarlos directamente con los ataques "guerrilleros" en la ciudad, sin establecer diferencia alguna. Sin duda, los objetivos del anticomunismo se desarrollaron como habían sido planteados, utilizando como estrategia el manejo ideológico, por un lado, y, por otro, las estructuras institucionales de los Estados, recurso económico con un alcance internacional al que fue difícil hacer frente desde los partidos, movimientos o liderazgos de izquierda definidos.

Finalmente, el último número de la revista Replica, el doscientos cuatro, publicado en noviembre de 1987, se puede entender mejor si se hace referencia al contexto internacional que se estaba viviendo, dado que preparaba el mayor cambio de la geopolítica vivida hasta entonces y que pondría fin a la Guerra Fría: dos años después, el 10 de noviembre de 1989, caería el muro de Berlín, y en la URSS desde 1985, 
con el último secretario del Partido Comunista de la Unión Soviética Mijaíl Gorbachov, se habían iniciado una serie de reformas con la perestroika (reestructuración) y la glásnost (apertura, transparencia) que llevarían a la disolución de la URSS y, con ello, al repliegue del comunismo y de la amenaza global de la ola roja. Del comunismo sólo quedó finalmente el desprestigio y su desuso por un largo proceso.

\section{Reflexiones finales}

Resulta de interés la manera en que se organizaron en este periodo los grupos de la derecha y ultraderecha de la entidad al converger en el movimiento anticomunista, dado que, generalmente, operan de manera imperceptible para la sociedad.

Sin embargo, en Jalisco con el grupo de los tecos de la UAG se estableció el centro de operaciones más importante de México, de América Latina y del mundo de la estrategia anticomunista internacional, evidenciándose públicamente a través de su principal arma ideológica: la revista Réplica.

En este instrumento de difusión se evidenciaron la organización, la construcción de un imaginario social del comunismo, la percepción que la derecha tuvo del comunismo, así como los alcances que tuvo el movimiento en Guadalajara, en México y en el mundo.

Las prácticas del anticomunismo no sólo se limitaron a lo ideológico, sino que también el espionaje, la infiltración, así como el entrenamiento militar entre sus militantes fueron los elementos que permitieron la persecución de los comunistas.

Con lo hasta aquí analizado se deduce que el anticomunismo fue una estrategia internacional liderada por Estados Unidos en el periodo de la Guerra Fría, y que se constituyó en uno de los principales enclaves de la doctrina de seguri- 
dad nacional, aplicada prácticamente a todo el continente y que magnificó al comunismo.

En cierta forma, el imaginario que se construyó sobre el comunismo y el PCM, a través de la tergiversación de la ideología comunista y de la siembra del miedo en la población en aras de lo que los anticomunistas consideraban un mejor futuro, legitimó el uso de la fuerza y de la represión a los grupos disidentes, en específico a los militantes comunistas mexicanos.

Por ello, el clima sociopolítico en que se desarrolló el PCM en Jalisco fue complicado y da algunas pautas para entender las situaciones que tuvo que sortear para lograr su permanencia en la entidad. Con ello, a su vez, se comprende lo delicado en los procesos de selección e ingreso para quienes buscaban militar en él, y, desde luego, las expulsiones que se generaron, fuente de estudios que en un futuro valdría la pena analizar, puesto que el anticomunismo fue un actor importante que estuvo presente durante gran parte de su trayectoria, es decir, no se puede sólo señalar este a partir del surgimiento formal de la FEMACO, sino a través de su manifestación en una práctica cotidiana del Estado hacia el partido.

Con la creación formal del movimiento anticomunista, el PCM y la izquierda en general enfrentaron dos frentes muy fuertes con los que no tuvieron cómo compararse en tanto su potencial para el uso e implementación de estrategias de destrucción o de conspiración: por un lado, estuvo el Estado, caracterizado por el uso excesivo de la violencia, la desaparición forzada, el espionaje y el uso de la fuerza hacia toda práctica de disidencia social y política; y por otro lado, un importante sector de la sociedad civil, que simpatizó con el movimiento anticomunista y que hizo mucho más fácil implementar ese espionaje, la infiltración, la persecución y la construcción de un imaginario social que a la fecha impera en muchos sectores de la población de la entidad, quienes 
siguen estigmatizando al comunismo y a la izquierda como los enemigos del desarrollo y de la estabilidad social.

En la sociedad jalisciense, el imaginario construido por el anticomunismo sobre el comunismo aún sigue teniendo un peso negativo, dado que se ha entendido como fracaso la desaparición de la URSS y el proyecto de la Revolución cubana, y se ha logrado establecer un sistema neoliberal y capitalista sin contrapeso, y dado que con el tiempo se logró erradicar al comunismo como una opción política para la sociedad mexicana y jalisciense.

Sin duda es un tema fascinante, que deja una serie de interrogantes, entre ellos el explicar por qué fueron los tecos su principal centro de operación para México, América Latina y el mundo, y aún están por explorarse a fondo los orígenes de este movimiento, quiénes fueron sus simpatizantes, a qué corrientes ideológicas pertenecían, cuáles eran los arreglos político-económicos, tanto nacional como internacionalmente, cuál es el estado actual del anticomunismo, cómo es que el Estado mexicano se vincula al anticomunismo, qué paso con este movimiento después de la Guerra Fría, etcétera.

Aguilar Camín, H., y Meyer, L. (1995). A la sombra de la Bibliografía Revolución mexicana. México: Editorial Cal y Arena.

Carrasco Gutiérrez, L. (1999). La guerrilla en México, 19701976. El caso de la Liga Comunista 23 de Septiembre (LC-23) (tesis de maestría inédita). Universidad de Guadalajara: Guadalajara.

Comisión Nacional de Derechos Humanos (2009). Recomendación 007/2009. Recuperado de: http://www.cndh. org.mx/recomen/2009/007.html

De Dios Corona, S. R. (2004). La historia que no pudieron borrar. México: La Casa del Mago. 
Bibliografía

Desaparecidos 2 (23 de abril de 20I3). Informe sobre la situación de desaparición forzada en México ante la CIDH 2013. Recuperado de: http://desaparecidos.espora.org/ spip.php?article952

Dorantes, A. (1993). El conflicto universitario en Guadalajara. México: Secretaría de Cultura del Gobierno del estado de Jalisco/Instituto Nacional de Antropología e Historia.

El Informador (29 de septiembre de 1968). "El pueblo de México derrotó al comunismo. El presidente y el Ejército dignos servidores de la patria", p. 8-A.

(06 de agosto de 1977a). "El procurador de Justicia de Jalisco y su Watergate. Estudiantes anticomunistas nuevos presos políticos", p. II-A.

— (08 de agosto de 1977b). "A la opinión pública", p. I-A.

Ecured (s/f). "Revolución cubana. Hecho histórico". Recuperado de: http://www.ecured.cu/index.php/ Revoluci\%C3\%B3n_Cubana\#Triunfo_de_la_revoluci. C3.B3n

Gamiño Muñoz, R. (2006). Del barrio a la guerrilla: historia de la Liga Comunista 23 de Septiembre (Guadalajara, 19641973). México: Libros Centro de Documentación de los Movimientos Armados (CEDEMA).

— y Toledo González, M. P. (20I I). "Origen de la Liga Comunista 23 de Septiembre". Revista Espiral. Estudios sobre Estado y Sociedad, I8(52), 9-36. Recuperado de: http://www.revistascientificas.udg.mx/index.php/EEES/ article/view/903/860

Gil Olivo, R. (2008). "Orígenes de la guerrilla en Guadalajara en la década de los setenta", en V. Oikión Solano, y $M$. E. García Ugarte (eds.), Movimientos armados en México, siglo XX. Volumen II (pp. 549-566). Zamora: El Colegio de Michoacán, CIESAS.

Gott, R. (197I). Guerrilla movements in Latin America. Garden City: Doubleday. 
Krauze, E. (1999). México siglo XX. El sexenio de Díaz Ordaz. Bibliografía México: Editorial Clío.

(2002). La presidencia imperial. Ascenso y caída del sistema político mexicano (1940-1996). México: Fábula TusQuest Editores.

Leal Buitrago, F. (2003). "La doctrina de seguridad nacional: materialización de la Guerra Fría en América del Sur". Revista de Estudios Sociales, (I5), 74-87.

López Macedonio, M. N. (2010). "Historia de una colaboración anticomunista transnacional. Los tecos de la Universidad Autónoma de Guadalajara y el Gobierno de Chiang Kai-Shek a principios de los años setenta". Contemporánea. Historia y problemas del siglo XX, I, I33158. Recuperado de: http://www.geipar.udelar.edu.uy/ wp-content/uploads/2012/05/09_Dossier07.pdf

Maza, E. ( I986). "Estados Unidos financió el crecimiento de la UAG. Los tecos, jefes de la organización nazi la Mano Blanca, en América Latina". Revista Proceso. Recuperado de: http://www.proceso.com.mx/l44003/estadosunidos-financio-el-crecimiento-de-la-uag

Montemayor, C. (2008). "Lo personal y lo real". Revista Proceso, (1666), $4 \mathrm{I}-45$.

(2009). "Los caídos en Tlatelolco". Revista Proceso, (1687), 46-49.

(20I2). "La Fiscalía especial”, en, La guerrilla recurrente (pp. 159 y ss.). México: Debate.

Morales Hernández, J. J. (2007). Memorias de un guerrillero, la guerra sucia del México de los 70. Guadalajara: edición del autor.

Moreno González, M. G. ( 10 de diciembre de 2007). Entrevista a Samuel Meléndrez. Guadalajara, Jal.

(2008). Entrevista personal con Samuel Meléndrez. Guadalajara, Jal.

(2016). Aproximación al Partido Comunista en Jalisco (1926-198I). México: El Colegio de Jalisco. 
Bibliografía
Muriá, J. M. (2000). Breve Historia de Jalisco. México: Colegio de México-Fondo de Cultura Económica.

Organización de Estados Americanos (1967). Alianza para el progreso. Washington: Unión Panamericana, Secretaría General de OEA. Recuperado de: www.fcpolit. unr.edu.ar/trabajosocial I/files/20 I3/09/Alianza-parael-Progreso-I.pdf

Paredes, A. (2004). "La Operación Cóndor y la guerra fría". Universum (Talca), 19(I), I22-I37. doi: https://dx.doi. org/I0.4067/S07 I 8-23762004000 I 00007

Petras, J. (2013). Latin America: Class Struggle and Resistance in the Age of Extractive Capitalism. Recuperado de: http:// petras.lahaine.org/? $p=1949$

Porto, C. W., y Hocsman, L. D. (coord.) (2016). Despojos y resistencias en América Latina. Buenos Aires: Estudios Sociológicos Editora. Recuperado de: http:// es.slideshare.net/juancarlosgomezjaramillo9/despojosy-resistencias-en-america-latina

Prieto, A. (2007). Las guerrillas contemporáneas en América Latina. México: Editorial Ocean Sur.

Revista Réplica (noviembre de 1967a). I(I).

(diciembre de 1967b). I(2).

- (octubre de 1968). 2(9).

(junio de 1969a). 2(14).

(agosto de 1969b). 2(15).

- (octubre de 1972a). 2(39).

(diciembre de 1972b). (4I).

(agosto de 1973a). (49).

(diciembre de 1973b). (53).

- (enero de 1974a). (54).

- (febrero de 1974b). (55).

(marzo de 1974c). (56).

Robles Garnica, H. G. (20I3). La guerrilla olvidada. Historia de una página manchada con sangre de estudiantes de la 
Universidad de Guadalajara. México: Taller Editorial La casa del Mago.

Romero, L. (1986). "La derecha. El movimiento fascista en Guadalajara”, en J. Tamayo (coord.), Perspectivas de los movimientos sociales en la región centro-occidente (pp. 31-102). México: Editorial Línea-Institutos de Estudios Sociales-Universidad de Guadalajara-Instituto de Investigaciones Sociales UNAM.

_ (1988). "Los estudiantes entre el socialismo y el neoconservadurismo”, en M. Aldana Rendón (coord.), Jalisco desde la Revolución. Tomo V: Movimientos sociales 1929-1940 (pp. 263-343). Guadalajara: Gobierno del Estado de Jalisco-Universidad de Guadalajara.

Santamarina Gómez, A. (1982). "El viraje de la izquierda mexicana en cuarenta años". Nexos, s/p.

Tamayo Rodríguez, J., y Moreno González, G. (20I3). "Trayectoria del movimiento estudiantil”, en G. Hernández Obledo (coord.), Universidad de Guadalajara: más de dos siglos de historia (pp. 299-326). México: Editorial Universitaria, Red de Universidad Mexicana, Consorcio de Universidades Mexicanas.

Touraine, A. (1997). Podremos vivir juntos. México: Editorial Fondo de Cultura Económica.

Trejo Delarbre, R. (1978). "El movimiento de los electricistas democráticos (1972-1978)”. Cuadernos Políticos, (18), 47-70. Recuperado de: https://rtrejo.files. wordpress.com/.../el-movimiento-de-los-electricistasdemocrc3al tic

Velázquez Rivera, E. J. (2002). "Historia de la doctrina de seguridad nacional”. Convergencia. Revista de Ciencias Sociales, 9(27), II-39.

Vocero Marxista de los Trabajadores y la Juventud (s/f). La izquierda socialista. Corriente Marxista Internacional. Recuperado de: http://www.laizquierdasocialista.org/ node/3062 